\title{
10
}

\section{VIABILIDADE CLÍNICA DO MÉTODO OCLUSÃO VASCULAR E PERSPECTIVAS PARA O FUTURO}

O desenvolvimento do método apresenta grande aplicabilidade e significância clínica, pois pode ser introduzido em cenários onde o treinamento de alta intensidade não será adequado. No entanto, uma das grandes preocupações com o treinamento são associadas as respostas adversas cardiovasculares, formação de trombo, dano vascular, dano sobre o nervo e dano muscular (LOENNEKE et al., 2014; MANINI; CLARK, 2009).

A teoria de Hormese pode ser aplicada ao treinamento com oclusão vascular onde doses baixas e moderadas de oclusão vascular produzem efeitos benéficos, ao passo que, altas pressões diminuirão os benefícios do método e aumentarão os riscos para a saúde do paciente (LOENNEKE et al., 2014; MANINI; CLARK, 2009). Considerando ainda que temos dados limitados sobre a temática e principalmente sobre sua segurança. Devemos ter cautela quanto a necessidade de sua aplicação imediata. Portanto, necessitamos de mais estudos a longo prazo para avaliação de sua segurança e viabilidade em populações que já apresentam fatores de risco cardiovascular (LOENNEKE et al., 2014; MANINI; CLARK, 2009).

A própria escala de 0 a 10 recomendada nesse livro foi originalmente desenvolvida para jovens homens que já praticavam treinamento resistido e mais trabalhos são necessários para determinar se a escala pode ser apropriadamente aplicada em outras populaçôes (MATTOCKS et al., 2018). Com isso, uma alternativa a escala, será apalpar a artéria radial (membros superiores) ou a artéria tibial posterior (membros inferiores) para verificar se existe pulsação durante a prática clínica (MATTOCKS et al., 2018). 
A largura do manguito, tipo de material e características do aluno possuem efeitos sobre a quantidade de pressão que deverá ser exercida para a restrição do fluxo sanguíneo e a prática de aplicar a mesma pressão absoluta para todas as pessoas deve ser desencorajada (MATTOCKS et al., 2018).

É muito importante que o leitor estude afundo o método antes de sua aplicação em populações clínicas ou atletas. Além disso, procurar a opinião de especialistas ATUALIZADOS no assunto será fundamental. Portanto, a atualização constante na área e leitura de artigos científicos sobre a temática é essencial para o profissional que deseja fazer uso desse método. O livro sempre será apenas uma parte resumida das informações e consequentemente passível de viés.

\section{REFERÊNCIAS BIBLIOGRÁFICAS}

LOENNEKE, J. P. et al. Blood flow restriction pressure recommendations: the hormesis hypothesis. Medical hypotheses, v. 82, n. 5, p. 623-626, 2014. MANINI, Todd M.; CLARK, Brian C. Blood flow restricted exercise and skeletal muscle health. Exercise and sport sciences reviews, v. 37, n. 2, p. 78-85, 2009.

MATTOCKS, Kevin T. et al. The Application of Blood Flow Restriction: Lessons From the Laboratory. Current sports medicine reports, v. 17, n. 4, p. 129-134, 2018. 